\title{
«ABAJO TODO: FUERA SEÑORÍOS Y SUS EFECTOS» \\ EL DECRETO DE 6 DE AGOSTO \\ DE 1811
}

REMEDIOS MORÁN MARTÍN 
SUMARIO

1. INCORPORACIÓN, SUPRESIÓN, ABOLICIÓN. 2. EL PLANTEAMIENTO DEL TEMA EN EL DEBATE PARLAMENTARIO. 3. SOBRE LO EXPRESO Y LO TÁCITO EN EL DECRETO DE 6 DE AGOSTO DE 1811. 4. REFLEXIONES FINALES. 


\title{
«ABAJO TODO: FUERA SEÑORÍOS Y SUS EFECTOS» EL DECRETO DE 6 DE AGOSTO DE 1811
}

\author{
POR \\ REMEDIOS MORÁN MARTIIN \\ Profesora Titular de Historia del Derecho y de las Instituciones \\ Departamento de Servicios Sociales y Fundamentos Histórico Jurídicos \\ UNED \\ rmoran@der.uned.es
}

\section{INCORPORACIÓN, SUPRESIÓN, ABOLICIÓN}

Con las palabras iniciales del título de este trabajo, respondía el diputado García Herreros en la sesión de las Cortes constituyentes de Cádiz a una propuesta por escrito presentada el mismo día por el diputado Alonso y López en el que, ante la necesidad de recursos proponía, con una serie de cautelas, la reversión a la Corona de los tributos y las tierras enajenadas de ésta durante siglos, propuesta que debe ser el punto de partida del tema que aquí analizo.

${ }^{1}$ Diario de Sesiones de las Cortes de Cádiz, 1 de junio de 1811, p. 1.161. Desde ahora cito DS y la fecha y página de la edición digitalizada, si bien difiere de la edición en papel, cuya referencia aparece indicada en cada página al ser facsimilar. Utilizo la edición digitalizada que puede consultarse a partir de la sesión de 1 de junio de 1810 en:

http://bib.cervantesvirtual.com/servlet/SirveObras/01593630013496031870035/ima0821.htm 
Al Decreto de 6 de agosto de 1811 se le conoce habitualmente como el decreto de abolición del régimen señorial en España, siendo los sucesivos decretos y leyes sobre el tema meramente aclaratorios o conclusivos del proceso, fundamentalmente la Ley de 3 de mayo de 1823, que es aclaratoria del primer decreto de 1811, según consta en sus primeras líneas o la Ley de 26 de agosto de 1837 que pone fin, aclarando o imponiendo, en su caso, los asuntos pendientes hasta ese momento.

Asimismo, los diferentes trabajos sobre el tema suelen denominarse con alguno de estos conceptos: incorporación de señoríos, supresión de señoríos, abolición de señoríos o disolución del régimen señorial. Siendo los primeros generalmente trabajos monográficos sobre un señorío en particular y los otros obras más generales sobre el proceso.

Con el presente trabajo pretendo hacer una aportación más al debate que se entabló desde 1811 en el seno de las Cortes y posteriormente a nivel de investigación sobre este complejo problema, intentando analizar el contenido mismo del Decreto de 1811 y el motivo de las dos leyes posteriores aclaratorias, enmarcando dicho análisis en el momento en el que se desarrolló, los problemas que suponía y las soluciones que se arbitraron, pero de modo principal mediante un análisis de las diferencias conceptuales entre los diferentes vocablos enunciados y las consecuencias jurídicas que suponía, exigiéndose, asimismo, diversa técnica jurídica en cada caso.

Para esto, voy a intentar analizar de forma casi exhaustiva los conceptos que utiliza el Decreto de 6 de agosto de 1811, puesto que maneja una especie de yuxtaposición integrando perfectamente los conceptos de «incorporación»y «abolición», dependiendo de la materia a la que se refiera. Aunque dicho Decreto está muy reproducido, lo incluyo como documento final, junto con las propuestas y proyecto presentado en las Cortes por la Comisión de señoríos, porque haré frecuentes referencias y porque son imprescindibles para comprender el alcance del debate parlamentario en el seno de las Cortes de Cádiz sobre el tema que nos ocupa. Tuvo como consecuencia la aclaración a dicho decreto, presentada a las Cortes en 1813 y la Real Cédula de 15 de septiembre de 1814, así como la exigencia de la promulgación de nuevas leyes en los periodos liberales, como las de 3 de mayo de 1823 y 26 de agosto de 1837, aclaratorias del Decreto de 6 de agosto, que es el objeto de análisis fundamental en este trabajo.

El primer concepto que aparece en el Decreto de 6 de agosto en su artículo primero es incorporación: «Desde ahora quedan incorporados a la Nación todos los señoríos jurisdiccionales, de cualquier clase y condición que sean», que también utiliza en el artículo 5. Sin embargo, en los artículos 4 y 7 decreta abolidos una serie de términos, como vasallos y vasallaje, las prestaciones derivadas de ellos y 
los privilegios exclusivos, privativos o prohibitivos que tengan su origen en el señorío ${ }^{2}$ (Véase decreto completo en Documento 3). Sin embargo, en este segundo caso, tras decretar la abolición de tales derechos y prestaciones, hace las respectivas excepciones, difuminando la línea de separación entre señorío y propiedad privada. Por lo tanto, el mismo hecho de incorporar o abolir y en este segundo caso de excepcionar determinados aspectos de la abolición, complica enormemente el tema.

Asimismo, durante el debate parlamentario se baraja también el concepto de reversión, que está en la mente de los parlamentarios respecto a los bienes egredidos de la Corona en diferentes momentos. Reversión no puede identificarse con incorporación, puesto que revertir supone que fue inicialmente separado y con posterioridad vuelve a la situación inicial, mientras que incorporar no significa que fuera necesariamente una parte desprendida o egredida, en este caso de la Corona. Por lo tanto es más acotada la expresión reversión que incorporación.

Cuestión diferente, aunque con puntos de contacto, es la desamortización ${ }^{3}$. Régimen señorial no coincide con amortización, excepto en el caso de los señoríos eclesiásticos y cuando parte de los bienes de señorío secular son vinculados en un mayorazgo, lo cual se hizo de forma frecuente, pero que, en este caso, la disposición de Cortes de 27 de septiembre de 1820 de supresión de todas las vinculaciones existentes en España, dividiéndolas por mitad entre el actual poseedor y su sucesor inmediato, permitió que ambos desde ese momento pudieran disponer de tales bienes con total libertad, derogada por Fernando VII, pero de nuevo revalidada por la Ley de 30 de agosto de 1836 y definitivamente en 1841. Por lo tanto, desvinculación de mayorazgos camina de forma paralela e independiente a la abolición del régimen señorial, de modo que beneficia siempre a los señores y poseedores de mayorazgos, puesto que convierte en propiedad libre y revalorizada la que hasta el momento había estado vinculada.

Como es obvio, la diferenciación en el uso de los conceptos conllevan una reflexión por parte de los constituyentes gaditanos que en gran medida desvela, por una parte, la trayectoria por la que el régimen señorial se había ido desarrollando durante siglos y los sucesivos intentos por parte de la Corona de ir dismi-

2 «Artículo $4^{\circ}$. Quedan abolidos los dictados de vasallos y vasallaje y las prestaciones, así reales como personales, que deban su origen a título jurisdiccional, a excepción de los que procedan de contrato libre en uso del sagrado derecho de la propiedad».

3 Existe una amplísima bibliografía sobre este tema, sin embargo una visión más actualizada desde el punto de vista de las relaciones entre la Iglesia-Estado en este aspecto, puede verse en M. ${ }^{a}$ Teresa Regueiro García, Relaciones Iglesia-Estado: afrancesados y doceanistas, Tirant lo Blanch, Valencia, 2011, especialmente cap. I epígrafe 4 y cap. II, epígrafe 5. 
nuyendo el ámbito de vigencia del régimen señorial, mediante las diferentes vías que consideraron posibles en cada momento y, por otro, el alto grado de desfiguramiento que en este momento tenían los conceptos que se enumeraban.

Sobre los diferentes momentos en los que se había acometido la restricción del régimen señorial, téngase en cuenta el ensayo de incorporación de señoríos a la Corona en el siglo XVI, después de las bulas y breves papales, que afectaron a señoríos eclesiásticos y de Órdenes militares o la creación de la denominada Junta de incorporación por Felipe V en $1706^{4}$. Como puede observarse, en ambos casos se utilizó el concepto de incorporación y cuando los intentos fueron sobre señoríos particulares, se utilizó indistintamente incorporación o reversión.

Como planteamiento previo, por tanto, se debe hacer una diferenciación entre los conceptos utilizados en cada caso:

Se utiliza incorporación, acción y efecto de incorporar, cuando se trata de agregar, por lo tanto unir algo a una cosa para conseguir otra única, de ahí que una de las formas de adquisición de la propiedad sea, precisamente, la accesión, si bien en este caso, no se trataría de esta figura jurídica, sino lo contrario, la vuelta de una parte separada de la principal.

Por el contrario, abolición, acción y efecto de abolir (del verbo aboleo, destruir, pero también suprimir, borrar) significa en Derecho dejar sin vigencia una ley, precepto o costumbre, por lo tanto la «destruye», resultando ser esta destrucción sinónima de derogar. En alguna ocasión se utiliza, finalmente, supresión, que puede considerarse como sinónimo de abolición, si bien se utiliza con cierto carácter de provisionalidad, mientras que cuando se abole o deroga implica una permanencia de futuro. En el mismo sentido de derogación de las leyes sobre un tema es la utilización del concepto de disolución, si bien se utiliza no para abolir un texto normativo, sino para erradicar un organismo o una institución, motivo por el cual se podría con rigor hacer referencia a la disolución del régimen señorial.

Este segundo sistema es el que se utilizó desde el decreto de la Revolución francesa de 4 de agosto de 1789, por el que quedan abolidos en Francia el «régimen feudal» ${ }^{5}$, que se extendió al resto de Europa a partir de este momento,

${ }^{4}$ Aunque hay muchas monografías sobre aspectos y señoríos concretos, sigue siendo referencia la clásica obra de Salvador de Moxó, La incorporación de los señoríos en la España del Antiguo régimen, Facultad de Filosofía y Letras de la Universidad de Valladolid, Valladolid, 1959. Sobre el significado de la Junta de Incorporación, vid., Remedios Morán Martín, «La Junta de Incorporación. Instrumento de la Nueva Planta», en E-Legal History Review, no 3, enero 2007, 22 pp. www.Iustel.com

5 Art. 1. L'Assemblée nationale détruit entièrement le régime féodal. Elle décrète que, dans les droits et les devoirs tant féodaux que censuels, ceux qui tiennent à la main-morte réelle ou personnelle, et à la servitude personnelle, et ceux qui les représentent, sont abolis sans indemnité; 
siendo el paradigma de abolición de lo que desde entonces se llamaron «Derechos feudales» ${ }^{6}$, si bien se recoge una compensación a los antiguos titulares. En este decreto se utiliza el término détruit entièrement, por lo tanto es el equivalente a nuestro abolición, en el mismo sentido de «suprimir» «destruir», «erradicar» los derechos feudales, que desaparecen desde el momento de la promulgación del decreto y de esta manera se recoge tanto en el artículo 98 del Estatuto de Bayona $^{7}$, como en los decretos de abolición de señoríos, promulgados por $\mathrm{Na}$ poleón en la España josefina, en los conocidos como Decretos de Chamartín, el 4 de diciembre de 1808, entre los que está el de abolición de los derechos señoriales ${ }^{8}$, antes de que el debate se planteara en las Cortes de Cádiz; decreto bonapartista que no tuvo el efecto esperado, fundamentalmente por la experiencia francesa y las diferentes circunstancias españolas, por lo que tuvo una serie de decretos aclaratorios y, finalmente, una marcha atrás en el proceso 9 .

et tous les autres sont déclarés rachetables, et le prix et le mode de rachat seront fixés par l'Assemblée nationale. Ceux desdits droits qui ne sont points supprimés par ce décret continueront néanmoins d'être perçus jusqu'au remboursement».

${ }^{6} \mathrm{Vid}$., L'abolition de la «feodalité» dans le monde occidental, coloquio internacional Toulouse, 12-16 novembre 1968, Paris, Editions du Centre National de la Recherche Scientifique, 1971, 2 vols. (una selección de comunicaciones en castellano, en Jacques Godechot y otros, La abolición del feudalismo en el mundo occidental,, Siglo XXI, Madrid, 1979).

7 «Artículo 98. La justicia se administrará en nombre del Rey, por juzgados y tribunales que él mismo establecerá. Por tanto, los tribunales que tienen atribuciones especiales, y todas las justicias de abadengo, órdenes y señorío, quedan suprimidas». Asimismo se recoge en los arts. 117 y ss. del Estatuto de Bayona la igualdad contributiva, etc. Vid., mi trabajo «Proyecto de abolición del régimen señorial en la legislación de José Bonaparte», en A Guerra peninsular. Perspectivas multidisciplinares. Congreso Internacional e interdisciplinar evocativo da Guerra Peninsular. XVII Colóquio de História Militar nos 200 anos das invasôes napoleónicas em Portugal, Comissâo portuguesa de Historia Militar-Centro de Estudios Anglo Portugueses, Lisboa, 2008, II, 675-691.

8 «Napoleón, Emperador de los franceses, Rey de Italia, y Protector de la Confederación del Rin. Hemos decretado y decretamos lo siguiente:

Artículo $1^{\circ}$. El Derecho feudal queda abolido en España desde la publicación del presente Decreto.

Artículo $2^{\circ}$. Toda carga personal, todos los derechos exclusivos de pesca, de almadrabas, $u$ otros derechos de la misma naturaleza en ríos grandes y pequeños, todos los derechos sobre hornos, molinos y posadas quedan suprimidos y se permite a todos, conformándose a las leyes, dar una extensión libre a su industria.

Artículo $3^{\circ}$. El presente decreto será publicado, y de él se hará registro en todos los Consejos, Audiencias y demás Tribunales para que se cumpla como Ley de Estado.

Lo firma Napoleón. Por el emperador, el Ministro Secretario de Estado Hugues B. Maret», Gazeta extraordinaria de Madrid, no 151, domingo 11 de diciembre de 1808, p. 1569.

9 Remedios Morán Martín, «Proyecto de abolición del régimen señorial en la legislación de José Bonaparte», o. c. 
Casi de forma paralela, el gobierno de la Regencia empieza a tomar medidas tendentes a la supresión de ciertos derechos, como el Real Decreto aboliendo las alcabalas, cientos y millones, promulgado en el Alcázar de Sevilla de 7 de agosto de $1809^{10}$ y otras que dan marcha atrás, como la derogación de los decretos bonapartistas citados ${ }^{11}$.

La utilización de la diferente técnica jurídica de incorporar, revertir o abolir tiene una enorme importancia para comprender el proceso que se siguió desde las Cortes constituyentes gaditanas en un tema de tanta relevancia y con consecuencias tan importantes para la consideración del sujeto del Derecho y la configuración del derecho de propiedad que surgiría a partir de este momento y cuyo resultado final no se fijará hasta el Código civil, según se irá analizando.

\section{EL PLANTEAMIENTO DEL TEMA EN EL DEBATE PARLAMENTARIO ${ }^{12}$}

En la sesión parlamentaria del 30 de marzo de 1811, el diputado valenciano Lloret y Martí, propuso el reintegro a la Corona de todas las jurisdicciones civiles y criminales ${ }^{13}$ apoyado por el diputado Joaquín Lorenzo Villanueva, en la misma sesión, para restituir a la Corona las ciudades, villas y lugares enajenados del Reino de Valencia, mediante «justa composición y tanteo», a la que se sumaron otros diputados pidiendo se acumulara la proposición Galicia y otros lugares, pasando el tema a la Comisión de Constitución ${ }^{14}$.

10 AHN, Reales Cédulas, Diversos, $\mathrm{n}^{\circ} 1.838$.

${ }_{11}$ Real decreto de la Suprema Junta Central de 25 de junio de 1809, AHN, Reales Cédulas, $\mathrm{n}^{0} 5.221$.

12 La exposición más amplia sobre el debate parlamentario y el proceso de abolición, Francisco J. Hernández Montalbán, La abolición de los señoríos en España (1811-1837), Biblioteca Nueva, Universitat de València, Valencia, 1999. Un estudio amplio sobre el tema, Barba Martín, José, Proceso de incorporación de señoríos a la Corona y abolición del régimen señorial, Tesis doctoral inédita, Departamenteo de Historia del Derecho y de las Instituciones, Universidad Complutense de Madrid, 2004. Agustín Ruiz Robledo, «La abolición de los señorios» en Revista de Derecho Político 20, 19831984, pp. 121-150.

${ }_{13}$ «Que desde luego se reintegren a la Corona todas las jurisdicciones, así civiles como criminales, consideradas para siempre como regalías de primera clase, o inherentes a la misma, sin perjuicio de establecerse en la hacedera Constitución lo que parezca más justo y conveniente acerca del reintegro o compensación que pueda hacerse a los que justifiquen haberla adquirido por contrato oneroso o causa remuneratoria», DS, 30 de marzo de 1811, p. 799.

14 Ibid., p. 800. Archivo de las Cortes, leg. 74, n 3, apud. Salvador de Moxó, La disolución del régimen señorial en España, o. c., p. 15. 
Posteriormente, en la sesión del 26 de abril de 1811, el diputado por Galicia Agustín Rodríguez Bahamonde, presentó una moción haciendo alusión a la aprobación de un decreto de 24 de septiembre de 1810 en el cual se proclamaba la soberanía de la Nación, lo que él consideraba ser contradictorio con la existencia de feudalismo y vasallaje de unos ciudadanos respecto a otros, pidiendo la abolición de tal sistema, por lo que presenta las siguientes proposiciones:

«Primera. Que V. M. por medio de decreto destierre para siempre el feudalismo y prohíba bajo la pena que sea de su agrado, que ninguna persona, sea de la clase y distinción que fuere, en lo sucesivo pueda exigir en razón de vasallage contribución alguna personal ni real de ningún español.

Segunda. Que si V. M. por alguna causa tuviese á bien diferir el decreto de abolición expresado que a lo menos mande suspender la cobranza de tan perjudiciales y detestables contribuciones feudales» ${ }^{15}$.

Sin embargo, fue en la sesión de primero de junio de 1811, cuando el Diputado por el reino de Galicia José Alonso y López, atento al debate sobre la necesidad de incremento de los recursos de la monarquía, presenta un escrito con la propuesta de reversión a la Corona de los bienes enajenados de ésta durante siglos y que habían provocado una continua disminución de los recursos de la monarquía. Distinguía tres formas de enajenación: en primer lugar, las ventas por precio menor; en segundo lugar la liberalidad de los reyes que habían cedido mediante donaciones gran parte del patrimonio de la Corona, tanto tierras como tributos y en tercer lugar las usurpaciones de bienes y derechos. Entre los bienes enajenados del real patrimonio, destaca el diputado, lo concerniente a la riqueza desmembrada del erario público como:

«Los derechos de tributos de tercias reales, talla, vasallaje, yantares, martiniegas, escribanías, portazgos, montazgos, pontages, peajes, pasages, rodas, asaduras, castillerías, borras, vereages y otros de esta naturaleza anegos a la Corona, que se cobraban antes por la Real Hacienda y que gozan aún muchos agraciados y corporaciones particulares por sus privilegios indebidamente adquiridos y mal concedidos, porque en la enajenación o merced del prédio o finca ha ido envuelto el derecho del cobro del tributo, mediante a que 'ge lo dio (el rey) con todos los pechos y con todas las rentas que á él solien dar et facer', dice la ley $9^{a}$ del título IV de la $5^{a}$ Partida».

15 Sesión de 26 de abril de 1811, DS, p. 935. 
Evalúa en 13.808 los señoríos existentes con enajenación de derechos y propone el diputado gallego tres medidas, amparándose en las normas de nuestro Derecho histórico ${ }^{16}$ :

a) Que se inste al Consejo de Castilla para que elabore en el menor tiempo posible un expediente en el cual figuren los derechos enajenados, sus poseedores y la cuantía de las indemnizaciones, según el derecho que tengan.

b) Que se inste al Consejo de Hacienda para que elabore otro expediente en el que se especifique los derechos de mayor cuantía enajenados, como tercias, escribanías, etc. y se especifique las posibles indemnizaciones, de modo que lo antes posible se restituyan al Erario.

c) Que desaparezcan los signos visibles de feudalismo, como horcas, argollas y otros símbolos y puesto que todos deben estar bajo una misma ley, hace uso de la ley de Partidas 4.26.3, en la que dice que nadie puede ser vasallo de dos señores.

Por lo tanto, considero que proponía tres pasos: elaboración de un expediente sobre los derechos enajenados y susceptibles de incorporación o reversión; la cuantificación de las indemnizaciones que corresponderían a los poseedores de dichos derechos y, finalmente, la desaparición de los símbolos del feudalismo. El primer y segundo paso suponía retrasar enormemente el proceso, volver a lo que ya se hizo con la Junta de Incorporación con Felipe V y se conocían los escasos resultados obtenidos y los nulos beneficios ni a corto ni a largo plazo. La última de las propuestas era relevante simbólicamente, pero a nada efectivo llevaba.

Manuel Antonio García Herreros, secretario de las Cortes y diputado por Soria, en respuesta al anterior, consideraba inútil tales expedientes, que para él ya estaban formados en el Consejo de Hacienda, sino que debieran simplemente concluirse con un simple renglón: «Abajo todo. Fuera los señoríos y sus efectos», sin embargo, puntualiza que a renglón seguido, se podría decir, para que no haya vejación a los interesados, que se deben presentar los títulos, de modo que los que son por título oneroso puedan ser reintegrados en su precio, teniéndose en cuenta que todo lo enajenado de la Corona tiene implícito un pacto de retro, que ahora se alegaría. En resumen, a pesar de esta puntualización, pide se tome una «medida radical».

${ }^{16}$ Novísima Recopilación, 3.5.2, 6 y 10. Se basa en la legitimación que supone que se recojan en la Novísima Recopilación preceptos desde Juan II en los cuales se declaran que se pueden revocar las mercedes hechas por los reyes durante periodos de tutorías, o las que se hicieron por mediación de privados, o bien, las prescripciones de los Reyes Católicos según las cuales se podrían revocar las dichas y se podrían adquirir las vendidas por precio menor, mediante reintegración del mismo. 
A partir de este inicial planteamiento de los dos diputados, sobre el que incidió el conde de Toreno, declarándose poseedor de señoríos, y otros diputados para que se fijen las posturas, especialmente de García Herreros, solicitando la aprobación de la medida por aclamación y sin discusión.

Las intervenciones se centran en la incorporación de señoríos a la Corona, evocando las formas anteriores con las que ésta intentó en varios momentos la incorporación concreta de señoríos, retomando el informe que se encuentra en el Consejo de Hacienda, a instancia de tres fiscales, de 15 de abril de 1776, en el que se alegaba el derecho preeminente de la Corona a reintegrar lo que de ella se había enajenado, haciéndolo por aclamación, sin discusión. Ante tal propuesta otros diputados intervienen alegando el perjuicio que supondría tales medidas para los titulares de señoríos, proponiendo se deje la discusión para el texto constitucional y no en este momento, puesto que supone la destrucción del sistema mismo que durante siglos ha tenido España ${ }^{17}$.

Planteadas así las cosas, sometida a votación la propuesta de José Alonso y López, no quedaron admitidas a discusión, por lo que García Herreros planteó la siguiente propuesta:

«Que las Cortes expidan un decreto que restituya a la Nación el goce de sus naturales, inherentes e imprescriptibles derechos, mandando que desde hoy queden incorporados a la Corona todos los señoríos, jurisdicciones, posesiones, fincas, y todo cuanto se haya enagenado o donado, reservando a los poseedores el reintegro a que tengan derecho que resultará del examen de los títulos de adquisición y de las mejoras, cuyos juicios no suspenderán los efectos del decreto» ${ }^{18}$.

Se suscitaron dos problemas a esta propuesta: que se cambiara «bienes de la Corona» por «bienes de la Nación» y la frase final de que no suspendieran los pleitos sobre derechos de las incorporaciones y que éstas se hicieran y se reintegraran las cantidades que correspondieran «cuando las circunstancias lo permitan».

A lo primero García Herreros alegaba que cambiar la titularidad supondría la posibilidad de iniciar disquisiciones legales en torno a los conceptos y de esta manera parecía claro lo que se pretendía. Respecto a lo segundo, el tema era más complejo, por lo que se dejó el debate de la propuesta para la sesión del día 4 de junio.

En esta sesión se produce la reacción de algunos de los procuradores procedentes de la nobleza, poseedores de señoríos, que presentaron un escrito en contra de la inmediatez y contundencia de la medida que se proponía.

17 Sesión de 1 de junio de 1811, DS, pp. 1.161-1.164.

18 Ibid., p. 1164. 
La discusión desde este momento se produce entre los diputados promotores de la proposición de abolición del régimen señorial, encabezados por García Herreros y los procedentes de la nobleza que consideraban la medida contra el orden público y la tradición histórica española, los derechos adquiridos y la exigencia de un análisis detenido sobre las consecuencias del tema. Finalmente, tras una discusión de algo más de un mes, el 9 de julio se nombró una Comisión formada por los diputados: García Herreros, Morales Gallego, Aparici, Ros y Aner, que presentaron la minuta del decreto en la sesión del día 31 de julio, discutiéndose el mismo en la sesión del 3 de agosto.

La propuesta de decreto a las Cortes para su discusión contenía varios elementos diferentes a los que habían sido las propuestas iniciales, la más evidente era la carga a los pueblos del precio a pagar por la incorporación de derechos señoriales que hubieran salido de la Corona por venta o pago de servicios.

Desde el principio de las propuestas, incluso la de García Herreros con su contundente frase que titula este trabajo, a renglón seguido daban un importante paso atrás en el proceso de reversión al mantener, en todo caso, la restitución del precio pagado o evaluado, más las mejoras, en los derechos enajenados. Esto diferencia sustancialmente la propuesta de Cádiz respecto de la de Bayona, puesto que en los decretos napoleónicos de 1809 en ningún caso observaban la restitución de precio alguno, incluso sobrepasando el modelo del decreto francés de 4 de agosto de 1789.

Es interesante analizar el debate parlamentario que siguió a la presentación del proyecto de Decreto por la Comisión el 3 de agosto de 1811. Se aprobaron tal como proponía la Comisión los artículos primero y segundo (con la misma numeración en el Decreto), igualmente el sexto, el séptimo, octavo, noveno, décimo, onceavo, doceavo, décimo cuarto y el décimo quinto (que pasan a tener diferente numeración). Sin embargo, son eliminados los artículos cuarto y quinto del proyecto y se añade uno completamente nuevo al Decreto, el décimo tercero, sobre la abstención de la vía jurisdiccional aplicable a los conflictos y se modifican sustancialmente, tras el debate parlamentario, los artículos 3 y 13 y lo que relacionado con éste en el 14.

En el debate se pasó directamente a examinar el artículo 3 del proyecto, referente a la continuidad en sus destinos de los corregidores, alcaldes mayores y demás empleados de los lugares de señorío, que se rechaza en la votación, permaneciendo solo los alcaldes ordinarios hasta final de año y, consecuentemente, los artículos 4 y 5 que estaban relacionados ${ }^{19}$.

\footnotetext{
19 DS, 3 de agosto de 1811, pp. 1.562-1.565.
} 
Sin embargo, el debate más extenso se llevó a cabo sobre el artículo 13, planteándose fundamentalmente quien debiera pagar los derechos que reviertan a la Nación, si los pueblos, como recoge el proyecto de decreto o la Nación, como proponen los parlamentarios y finalmente se vota y recoge en el Decreto ${ }^{20}$, así como el pago de un interés del $3 \%$ desde la publicación del decreto, que terminó recogiéndose en la segunda parte de éste ${ }^{21}$, cuyo contenido viene de lo recogido en el artículo 7 , referente a la conversión de propiedad particular en lo concerniente a los señoríos territoriales «lo que resultará de los títulos de adquisición», por lo tanto la pretensión de evaluar económicamente capital y mejoras. Finalmente se admitió un nuevo artículo, a propuesta del diputado Sr. Traver, que sería incluido en el decreto como artículo 13 del texto definitivo, que una vez promulgado no cierra el tema sino que, por el contrario, lo abre y lo mantiene en plena efervescencia durante todo el siglo XIX ${ }^{22}$.

Con esto tenemos los elementos necesarios para el análisis de la conceptualización utilizada y las vías abiertas para su ejecución.

\section{SOBRE LO EXPRESO Y LO TÁCITO EN EL DECRETO DE 6 DE AGOSTO DE 1811}

Los intentos de reversión de señoríos a la Corona no eran nuevos. La novedad que se plantea en las Cortes constituyentes gaditanas era la eliminación del régimen señorial como forma de egresión de derechos inalienables de la Corona, ahora de la Nación, y no la incorporación o reversión parcial, individualizada, de los señoríos que por causas concretas no se ajustaran a las condiciones de la donación o a la sucesión de sus titulares según los títulos constitutivos.

Desde este punto de vista, puede considerarse el primer precedente en España el proceso acometido por Carlos IV de incorporación a la Corona de señoríos eclesiásticos, coincidente en este punto con la desamortización eclesiástica que se produce simultáneamente, cuya formulación más clara es la recogida en

20 Ibid., pp. 1.566-1.572

${ }^{21}$ DS, 4 de agosto de 1811, pp. 1.577-1.583.

22 Véase las obras de referencia Rafael García de Ormaechea, Supervivencias feudales en España. Estudios de legislación y jurisprudencia sobre señoríos, Madrid, Ed. Reus, 1932; Salvador de Moxó, La disolución del régimen señorial en España, o. c. Agustín Ruiz Robledo, «La abolición de los señorios» en Revista de Derecho Político 20, 1983-1984, pp. 121-150 y Francisco J. Hernández Montalbán, La abolición de los señoríos en España, o. c., así como la Tesis doctoral inédita de José Barba Martín, Proceso de incorporación de señoríos a la Corona y abolición del régimen señorial, o. c. 
la Novísima Recopilación ${ }^{23}$. Desde mi punto de vista éste es el primer intento de gran alcance y global de incorporación de señoríos, aunque solo los eclesiásticos. Antes y después de este decreto se habían promulgado diferentes decretos de incorporación y desamortización de los bienes eclesiásticos, pero es especialmente relevante éste porque en él se engloba la incorporación a la Corona de los señoríos eclesiásticos, tanto en su aspecto territorial como jurisdiccional. Sin embargo, obsérvese que no se trata solo de los señoríos que han salido del patrimonio real, con evaluación de su valor y compensación en vales reales.

La importancia del Decreto de 25 de febrero de 1805 reside en dos cuestiones: primero que se trata de la incorporación tanto de lo territorial como de lo jurisdiccional, por consiguiente de todo lo egredido de la Corona y, en segundo lugar, que, al englobar todo, no abre el proceso de diferenciación entre lo territorial y lo jurisdiccional, evitando con ello cualquier tipo de recurso posterior sobre la diferenciación de las respectivas figuras (solo cabría sobre la evaluación del conjunto por la Hacienda real).

Sin embargo, conocido este precedente por los procuradores de las Cortes gaditanas, siendo los miembros de la Comisión buenos conocedores del tema, como lo demuestra el debate parlamentario, parece que hay una especie de continuada marcha atrás desde la proposición que realmente fue el punto de partida del decreto, la del diputado José Alonso y López seguida por la de García Herreros que tomó desde entonces el protagonismo. Desde la propuesta inicial de éste, que recuerda tanto al decreto de Carlos IV sobre incorporación de señoríos eclesiásticos a la Corona, proponiendo «que queden incorporados a la Corona todos los señoríos, jurisdicciones, posesiones, fincas, y todo cuanto se haya enagenado o donado, reservando a los poseedores el reintegro a que tengan derecho que resultará del examen de los títulos de adquisición y de las mejoras», hasta el decreto final, que reconduce la incorporación a lo jurisdiccional, convirtiendo en propiedad particular lo referente a los señoríos territoriales, se ha retrocedido mucho en lo que sería el objetivo de la Comisión encargada de extender el decreto sobre señoríos, creada en la sesión de 9 de julio.

Se evidencian tres cuestiones fundamentales de la Comisión, con claro retroceso respecto a la propuesta de partida formulada por García Herreros:

Por un lado, la poco contundente redacción de abolición de los señoríos jurisdiccionales que contiene el proyecto, manteniendo los cargos más relevantes durante el tiempo que resta del año.

${ }^{23}$ Don Carlos IV, en Aranjuez, por resolución a consejo de 30 de enero y cédula de la Cámara de 25 de febrero de 1805. Incorporación a la Corona de los Señoríos temporales y jurisdicciones enagenadas de ella y poseídas por las Mitras y otras dignidades eclesiásticas, Nov. Recop. 4.1.14. 
En segundo lugar, el considerar que el régimen señorial no era una detracción de funciones a la Corona (entonces ya a la Nación), sino que afectaba a los pueblos concretos sometidos a señorío, una especie de sujeción particular que afectaba a «algunos ciudadanos», de modo que la redacción del proyecto consideraba que tanto los oficios que se mantienen en el cargo durante el resto del año, como los pagos derivados de la presentación de los títulos por los señores debieran pagarlos dichos pueblos.

Finalmente, la conversión en propiedad particular lo que hasta el momento había sido "propiedad feudal» (si bien no con este nombre, sí se discute de esta manera en las sesiones de Cortes), debiéndose pagar la cuantía correspondiente de todo lo incorporado.

En la redacción final del decreto, se considerarán que los oficios que revierten a la Nación deben ser pagados por ésta y se matiza la forma de pago y el pago del capital e interés.

Tanto en un caso como en otro, la consecuencia es que queda incorporada a la Nación la jurisdicción, pero con evaluación y pago de sus derechos y el mantenimiento de los señoríos territoriales. En relación con la jurisdicción, en lo que se entiende nombramiento de oficios relacionados con la administración y justicia y de gobierno local y la misma impartición de justicia en segunda instancia, propia de los señores o sus delegados, se va a mantener la reversión, a pesar de las posteriores aclaraciones en Cortes y del tenor del decreto de 15 de diciembre de 1814, que paraliza la labor legislativa gaditana, pero que mantiene lo relativo a la jurisdicción y las posteriores leyes aclaratorias de 1820 y 1836 , se centrarán fundamentalmente en el perfilamiento de lo que son derechos territoriales, sin que la jurisdicción vuelva a ser ejercida por los señores.

No puede decirse lo mismo de lo que se considerará debe ser evaluado económicamente para la compensación a sus titulares, en cuyo aspecto el denominado «sagrado derecho de propiedad» que surgiría de la propuesta y se consagrará en el Decreto de 6 de agosto, hará que tanto derechos jurisdiccionales como territoriales sean reconocidos como derechos adquiridos de los señores y, por lo tanto, respetados por la Nación, revalorizados y evaluables.

Prueba de ello es la matización que se hace de los derechos privativos que se convierten en uso común de los pueblos, sin embargo se matiza su utilización como particulares, pero obviamente en los pueblos de señorío pertenecían a los señores, por lo que se convertirían igualmente en propiedad particular.

En este mismo sentido se pronuncia especialmente el diputado valenciano Pedro Aparici y Ortiz en el informe presentado a las Cortes en la sesión de 31 de marzo de 1813, sobre el alcance de la abolición de los derechos señoriales en 
el reino de Valencia ${ }^{24}$, que, si bien presenta peculiaridades respecto a este reino especialmente referida a los señores que se apropiaron de los bienes de los moriscos tras la expulsión de 1609, puede en gran parte ampliarse a otros territorios. Así, analizando los artículos 5 y 6 del Decreto de 6 de agosto de 1811 considera que más que «conseguir la Nación los alivios que desean sus Representantes, va a experimentar perjuicios de mucha consecuencia y de fatales resultados».

Se centra muy fundamentalmente Aparici en dos aspectos: la forma de apropiación de los señores de las tierras de los moriscos, fundamentalmente mediante cartas de población y, en segundo lugar, de la cesión a censo de dichas tierras para su cultivo, alegando tanto las directrices de Felipe II sobre dicha apropiación como las leyes que desde el siglo XVIII venían reduciendo el monto de pago de los censos.

Los perjuicios y resultados del decreto estaban revelándose desde el primer momento, con la interposición de numerosos pleitos por parte de los pueblos para que se ejecutara el decreto y por parte de los titulares del «señorío directo» para el reconocimiento de sus derechos como territoriales, alegando pactos para el reconocimiento como tales de los jurisdiccionales, que por tanto se convertirían en territoriales y, en todo caso, sería evaluables económicamente en caso de reversión.

Pero el tema era aún más arduo si se tiene en cuenta que en el siglo XVII la cesión a censo, figura elaborada por los juristas de la recepción del Derecho común con base en el Derecho romano, aún podría «catalogarse» entre las figuras de carácter territorial en los señoríos, sin embargo no se tenía en cuenta por parte del diputado Aparici los «pactos» que en condiciones de desigualdad (era el principio que primaba en el Antiguo régimen) se habían realizado entre señores y vasallos, de modo que aplicando la premisa del artículo 6 del decreto (arrastrado desde la primera propuesta de García Herreros), gran parte de los derechos jurisdiccionales, en los que había habido transacción con los vecinos de los lugares de señorío sobre su modo de pago, disminución, fechas, etc. pasarían a ser contrato particular.

\section{REFLEXIONES FINALES}

Las Cortes constitucionales gaditanas tuvieron que enfrentarse reiteradamente con los problemas derivados de la indefinición del Decreto de 6 de agosto, de

${ }^{24}$ DS, 31 de marzo de 1813, pp. 4.946-4.953. También reproducido por Salvador de Moxo, La abolición del régimen señorial en España, o.c., pp. 202-218. 
su confusa dejación, creo que medida, en cuanto a la presentación de títulos y consecuencias de los pactos sobre prestaciones. El tema señorial no podía resolverse dejando a la iniciativa particular y a la vía jurisdiccional cada caso.

En definitiva, creo que el Decreto de 6 de agosto de 1811 fue uno más de los momentos fallidos de resolución del problema que para la Corona, ahora para la Nación, suponía el régimen señorial, en cuanto vía de feudalismo. No supuso el inicio de la abolición del régimen señorial, solo en cierta medida de la reversión de parte de los derechos jurisdiccionales y del ejercicio de la jurisdicción por los señores, en este sentido solo quedó abolida la jurisdicción señorial, como jurisdicción especializada, pero no todos los derechos jurisdiccionales, porque algunos de ellos se seguiría debatiendo individualmente en cada señorío mediante la vía jurisdiccional, vía a la que se desvió, una vez más, la resolución de conflictos.

La vía legislativa se reveló incapaz de afrontar la abolición del régimen señorial. La conocida frase de García Herreros «Abajo todo: fuera señoríos y sus efectos» quedó de nuevo en una buena frase, dejando a la tortuosa vía jurisdiccional la erradicación paulatina del régimen señorial con sus efectos.

\section{DOCUMENTO 1}

Propuesta de García Herreros en la sesión de las Cortes de Cádiz de 5 de julio de 1811

Diario de Sesiones, n. ${ }^{\circ} 247$, p. 1.187

(ed. Cervantes virtual: http://bib.cervantesvirtual.com/servlet/SirveObras/01593630013496031870035/ima0843.htm)

«Antes de comenzarse la discusión sobre la proposición del Sr. Secretario García Herreros acerca de la abolición de señoríos y jurisdicciones, y reversión a la Nación de fincas enagenadas ó donadas (sesiones del $1^{\circ}$ y 4 de este mes), la propuso su autor explicada y extendida en las siguientes:

Primera. Habiendo declarado V. M. por su solemne decreto del memorable día 24 de Setiembre próximo que la soberanía reside inherentemente en la Nación, es ilegal, injusto y contradictorio que haya españoles que reconozcan y estén sujetos a otro señorío que el de la Nación, de que son parte integrante y que otros jueces que los nombrados por la Nación misma ejerzan la jurisdicción ordinaria: procede en todo rigor de justicia que desde hoy mismo queden incorporados a la Corona, o sea a la Nación, todos los señoríos jurisdiccionales, de cualquier clase y condición 
que sean, y que desde luego se proceda al nombramiento de todas las justicias de señorío y demás funcionarios públicos por el mismo orden que los llamados de realengo.

Segunda. Los señoríos territoriales y solariegos quedarán en la clase de los demás derechos de la propiedad particular, si por su naturaleza no son de los que deben incorporarse a la Corona, o no se hayan cumplido las condiciones con que se concedieron, lo que resultará de los títulos de adquisición.

Los contratos, pactos o convenios hechos en razón de aprovechamientos, arriendos de terrenos, censos u otros de esta especie celebrados entre los llamados señores y vasallos serán considerados como los demás particulares.

Tercera. Desde hoy mismo quedarán suprimidos y derogados todos los derechos privativos y exclusivos de caza, pesca, hornos, molinos, aprovechamiento de agua, pastos y demás de cualquiera clase que sean, quedando todo esto al libre uso de los hombres.

Cuarta. Todas las fincas enagenadas o donadas, que por su naturaleza contengan explícita o implícitamente la condición de retro o de reversión, quedarán incorporadas desde la fecha.

Ínterin la Nación reintegra el precio de la egresión y el aumento de las mejoras, si las hubiese, reconocerá el capital que resulta de ambas cantidades, y quedarán las mismas fincas hipotecadas al pago del rédito que se estipule, ínterin se redime el capital.

Quinto. Todo el que obtenga dichas prerrogativas por título oneroso será reintegrado por el precio de la egresión que resulte de los títulos de adquisición, y el aumento que resulte del juicio de mejoras.

Sexta. Ninguno podrá demandar a la Nación para el pago de lo adquirido por título oneroso sin acreditar que ha entregado los títulos originales y que ya esté realizada la incorporación.

Sétima. Los que en adelante osen llamarse señores de vasallos, ejerzan jurisdicción o nombren jueces, o usen de los privilegios y derechos de que hablan los capítulos precedentes, perderán el derecho al reintegro.

\section{DoCUMENTO 2}

Proyecto de decreto presentado a discusión por la Comisión de reversión de señoríos, en la sesión de Cortes de 3 de agosto de 1811 


\section{Decreto}

Deseando las Cortes generales y extraordinarias y extraordinarias del Reino remover los obstáculos que hayan podido oponerse al bien régimen, aumento de población y prosperidad de la Monarquía española, decretan:

1. Que desde hoy mismo queden incorporados a la Nación todos los señoríos jurisdiccionales de cualquier clase y condición que sean.

2. ${ }^{\circ}$ Se procederá al nombramiento de todas las justicias y demás funcionarios públicos, por el mismo orden y según se verifica en los pueblos de realengo.

3. ${ }^{\circ}$ Los corregidores, alcaldes mayores y demás empleados comprendidos en el artículo anterior, continuarán en sus destinos hasta el fin del presente año, sirviéndoles de título esta declaración y sus salarios se pagarán a prorrata de los fondos de los pueblos y en su defecto por repartimiento entre los vecinos.

4. ${ }^{\circ}$ En los pueblos en que a más de los empleados nombrados por el Gobierno hubiese otros de la misma clase nombrados por los dueños jurisdiccionales, cesarán estos desde la publicación de este decreto.

5. El Consejo de regencia tomará las providencias oportunas para designar los pueblos, en que por sus circunstancias deban conservarse o suprimirse los empleos de que hablan los artículos anteriores, para que en el primer caso proceda a su nombramiento; en inteligencia de que los actuales deben cesar el último día del presente año, aun en el caso de no estar hecha la designación.

6. Quedan abolidos los dictados de vasallo y vasallaje, y las prestaciones, así reales como personales, que deban su origen a título jurisdiccional, a excepción de las que procedan de contrato libre en uso del sagrado derecho de propiedad.

7. Los señoríos territoriales y solariegos, quedan desde ahora en la clase de los demás derechos de propiedad particular, si no son de aquellos que por su naturaleza deban incorporarse a la Nación o de los que no se hayan cumplido las condiciones con que se concedieron, lo que resultará de los títulos de adquisición.

8. Por lo mismo, los contratos, pactos o convenios que se hayan hecho en razón de aprovechamientos, arriendos de terrenos, censos u otras de esta especie, celebrados entre los llamados señores y vasallos, se deberán considerar desde ahora como contratos de particular a particular. 
9. Quedan abolidos los privilegios llamados exclusivos, privativos y prohibitivos, que tengan el mismo origen de señorío, como son los de caza, pesca, hornos, molinos, aprovechamientos de aguas, montes y demás, quedando al libre uso de los pueblos con arreglo al derecho común y a las reglas municipales establecidas en cada pueblo, sin que por esto los dueños se entiendan privados del uso que como particulares puedan hacer de los hornos, molinos y demás fincas de esta especie, ni de los aprovechamientos comunes de aguas, pastos, etc., a que en el mismo concepto puedan tener derecho en razón de vecindad.

$10 .^{\circ}$ Los que obtengan las prerrogativas indicadas en los antecedentes artículos por título oneroso, serán reintegrados del capital que resulte de los títulos de adquisición y los que los posean por recompensa de grandes servicios reconocidos, serán indemnizados de otro modo.

11. Los que se creen con derecho al reintegro, de que habla el artículo antecedente, presentarán sus títulos de adquisición en las Chancillerías y Audiencias del territorio, donde en lo sucesivo deberán promoverse, sustanciarse y finalizarse estos negocios en las dos instancias de vista y revista, con la preferencia que exige su importancia, salvos aquellos casos en que puedan tener lugar los recursos extraordinarios de que tratan las leyes, arreglándose en todo a lo declarado en este decreto y a las leyes que por su tenor no queden derogadas.

12. ${ }^{\circ}$ Para la indemnización que deba darse a los poseedores de dichos privilegios exclusivos por recompensa de grandes servicios reconocidos, procederá la justificación de esta calidad en el tribunal territorial correspondiente, y éste la consultará al Gobierno con remisión del expediente original, quien designará lo que debe hacerse consultándolo con las Cortes.

$13 .^{\circ}$ Los pueblos respectivos abonarán el capital que resulte de los títulos de adquisición o lo reconocerán otorgando la correspondiente escritura, abonando en ambos casos un 3 por 100 de intereses desde la publicación de este decreto hasta la redención de dicho capital.

14. En cualquiera tiempo que los poseedores presenten sus títulos serán oídos y los pueblos estarán a las resultas para las obligaciones de que habla el artículo anterior.

15. En adelante, nadie podrá llamarse señor de vasallos, ejercer jurisdicción, nombrar jueces, ni usar de los privilegios y derechos com- 
prendidos en este decreto, y el que lo hiciere perderá el derecho al reintegro en los casos que quedan indicados.

Lo tendrá entendido el Consejo de Regencia, y dispondrá lo necesario a su cumplimiento, haciéndolo imprimir, publicar y circular.

\section{DOCUMENTO 3}

Decreto de 6 de agosto de 1811 de incorporación de señoríos jurisdiccionales a la Nación; los territoriales quedarán como propiedades particulares; abolición de los privilegios exclusivos, privativos y probibitivos; modo de reintegrar a los que obtengan estas prerrogativas por título oneroso, o por recompensa de grandes servicios: nadie puede llamarse Señor de vasallos, ni exercer jurisdicción, etc.

Colección de decretos y órdenes que han expedido las Cortes generales y extraordinarias desde su instalación en 24 de septiembre de 1810 hasta igual fecha de 1811, Cádiz, Imprenta Real, 1811, pp. 193-196.

Deseando las Cortes generales y extraordinarias remover los obstáculos que hayan podido oponerse al buen régimen, aumento de población y prosperidad de la Monarquía española, decretan:

1. Desde ahora quedan incorporados a la Nación todos los señoríos jurisdiccionales, de cualquier clase y condición que sean.

2. ${ }^{\circ}$ Se procederá al nombramiento de todas las Justicias y demás funcionarios públicos, por el mismo orden, y según se verifica en los pueblos de realengo.

3. Los Corregidores, Alcaldes mayores y demás empleados comprehendidos en el artículo anterior, cesarán desde la publicación de este Decreto, a excepción de los Ayuntamientos y Alcaldes ordinarios, que permanecerán hasta fin del presente año.

4. ${ }^{\circ}$ Quedan abolidos los dictados de vasallo y vasallage, y las prestaciones así reales, como personales que deban su origen a título jurisdiccional, a excepción de las que procedan de contrato libre en uso del sagrado derecho de propiedad.

5. Los señoríos territoriales y solariegos quedan desde ahora en la clase de los demás derechos de propiedad particular, si no son de aquellos que por su naturaleza deban incorporarse a la Nación, o de los en que no se hayan cumplido las condiciones con que se concedieron, lo que resultará de los títulos de adquisición.

6. ${ }^{\circ}$ Por lo mismo los contratos, pactos o convenios que se hayan hecho en razón de aprovechamientos, arriendos de terrenos, censos, u otros de 
esta especie, celebrados entre los llamados Señores y Vasallos, se deberán considerar desde ahora como contratos de particular a particular.

7. ${ }^{\circ}$ Quedan abolidos los privilegios llamados exclusivos, privativos y prohibitivos, que tengan el mismo origen de Señorío, como son los de caza, pesca, hornos, molinos, aprovechamientos de aguas, montes y demás; quedando al libre uso de los pueblos, con arreglo al derecho común, y á las reglas municipales establecidas en cada pueblo; sin que por esto los dueños se entiendan privados del uso, que como particulares pueden hacer de los hornos, molinos y demás fincas de esta especie, ni de los aprovechamientos comunes de aguas, pastos y demás á que en el mismo concepto puedan tener derecho en razón de vecindad.

8. Los que obtengan las prerrogativas indicadas en los antecedentes artículos por título oneroso serán reintegrados del capital que resulte de los títulos de adquisición; y los que los posean por recompensa de grandes servicios reconocidos serán indemnizados de otro modo.

9. Los que se crean con derecho al reintegro, de que habla el artículo antecedente, presentarán sus títulos de adquisición en las Chancillerías y Audiencias del territorio, donde en lo sucesivo deberán promoverse, sustanciarse, y finalizarse estos negocios en las dos instancias de vista y revista con la preferencia que exige su importancia, salvo aquellos casos en que puedan tener lugar los recursos extraordinarios, de que tratan las leyes; arreglándose en todo a lo declarado en este Decreto, y a las leyes que por su tenor no queden derogadas.

10. Para la indemnización que deba darse a los poseedores de dichos privilegios exclusivos por recompensa de grandes servicios reconocidos, procederá la justificación de esta calidad en el Tribunal territorial correspondiente, y este la consultará al Gobierno con remisión del expediente original, quien designará lo que deba hacerse, consultándolo con las Cortes.

11. La Nación abonará el capital que resulte de los títulos de adquisición, o lo reconocerá, otorgando la correspondiente escritura; abonando en ambos casos un tres por ciento de intereses desde la publicación de este Decreto, hasta la redención de dicho capital.

12. En qualquier tiempo que los poseedores presenten sus títulos, serán oídos, y la Nación estará á las resultas para las obligaciones de que habla el artículo anterior. 
$13 .^{\circ}$ No se admitirá demanda ni contestación alguna que impida el puntual cumplimiento, y pronta execución de todo lo mandado en los artículos anteriores, sobreseyéndose en los pleytos que haya pendientes; llevándose inmediatamente a efecto lo mandado, según el literal tenor de este Decreto, que es la regla que en lo sucesivo debe gobernar para la decisión; y si se ofreciese alguna duda sobre su inteligencia y verdadero sentido, se abstendrán los Tribunales de resolver é interpretar, y consultarán a S. M. por medio del Consejo de Regencia, con remisión del espediente original.

$14{ }^{\circ}$ En adelante nadie podrá llamarse Señor de vasallos, exercer jurisdicción, nombrar Jueces, ni usar de los privilegios y derechos comprehendidos en este Decreto; y el que lo hiciere perderá el derecho al reintegro en los casos que quedan indicados.

Lo tendrá entendido el Consejo de Regencia, y dispondrá lo necesario a su cumplimiento, haciéndolo imprimir, publicar y circular.- Juan José Guereña, Presidente.- Ramon Utges, diputado secretario.- Manuel García Herreros, Diputado Secretario-. Dado en Cádiz a 6 de Agosto de 1811.- Al Consejo de Regencia. Reg. Fol. 126 y 127.

Title:

«DOWN WITH EVERYTHING. OFF WITH LORDSHIPS AND THEIRS EFFECTS» THE AUGUST 6, 1811 ACT

\section{Summary:}

1. Addition, deletion, abolition. 2. The approach the issue in the parliamentary debate. 3. Express what it implied in the decree of August 6, 1811. 4. Final thoughts.

\section{Resumen:}

Para conocer los pasos iniciales del proceso de abolición del régimen señorial en España, resulta imprescindible realizar un intento de comprensión de la técnica jurídica utilizada en el periodo constituyente de las Cortes de Cádiz y en los años posteriores de gobiernos liberales. La reflexión sobre este tema es el objeto del presente trabajo.

\section{Abstract:}

For the initial steps of the process of abolition of the feudal regime in Spain, is essential to make an attempt to understand the legal technique 
used in the period of the Constituent Courts of Cadiz and in the later years of liberal governments. The debate on this issue is the subject of this work.

\section{Palabras clave:}

Abolición régimen señorial. Siglo XIX, Constitución de Cádiz, Decreto de 6 de agosto de 1810.

\section{Key words:}

Lordship regime abolishment, $19^{\text {th }}$ Century, Constitution of Cadiz, The August 6, 1811 Act. 